\title{
Sorption of Ammonium Ions onto Natural and Modified Egyptian Kaolinites: Kinetic and Equilibrium Studies
}

\author{
Ola I. El-Shafey, Nady A. Fathy, and Thoria A. El-Nabarawy \\ Physical Chemistry Department, Laboratory of Surface Chemistry and Catalysis, National Research Center, Dokki, Cairo 12622, Egypt \\ Correspondence should be addressed to Thoria A. El-Nabarawy; thoriaelnabarawy@yahoo.com
}

Received 26 December 2013; Revised 20 March 2014; Accepted 31 March 2014; Published 24 April 2014

Academic Editor: Taicheng An

Copyright (C) 2014 Ola I. El-Shafey et al. This is an open access article distributed under the Creative Commons Attribution License, which permits unrestricted use, distribution, and reproduction in any medium, provided the original work is properly cited.

\begin{abstract}
Thermally activated, acid-activated, and acid-leached of thermally activated kaolinites were prepared from the Egyptian ore. The physical and chemical properties were studied using $\mathrm{N}_{2}$ sorption at $-196^{\circ} \mathrm{C}$, FTIR, SEM, and the total surface acidity. The sorption of $\mathrm{NH}_{4}{ }^{+}$ions on the investigated sorbents was controlled with the solution $\mathrm{pH}$, sorbent dosage, and initial concentration of $\mathrm{NH}_{4}{ }^{+}$ solution. Kinetic and equilibrium $\mathrm{NH}_{4}{ }^{+}$sorption at $30^{\circ} \mathrm{C}$ were employed. Four kinetic models were applied to the kinetic sorption data; pseudo-second-order, Elovich, and intraparticle diffusion models fitted well the kinetic data whereas pseudo-first-order model was less applicable. Elovich parameters refer to physical sorption type of $\mathrm{NH}_{4}{ }^{+}$on nonuniform sites and the intraparticle diffusion controls the sorption of $\mathrm{NH}_{4}^{+}$by kaolinites to a small extent. The equilibrium sorption data followed Langmuir and D- $\mathrm{R}$ models; the negative value of $\Delta G$ indicates a spontaneous sorption and the mean sorption energy obtained shows also physical sorption. The sorption capacities of nonactivated and activated Egyptian kaolinites towards $\mathrm{NH}_{4}^{+}$sorption $\left(10.87-45.45 \mathrm{mg} \cdot \mathrm{g}^{-1}\right.$ ) were good sorbents as compared with those uptaken by other clays reported in the literature and proved to be more active besides being less expensive and highly available.
\end{abstract}

\section{Introduction}

Ammonium $\left(\mathrm{NH}_{4}{ }^{+}\right)$is one of the most common nitrogenous pollutants in wastewater as well as in groundwater and agricultural water [1]. Also, ammonium is the inorganic ion form of nitrogen pollution contained in municipal sewage, industrial wastewater, and agricultural wastes or decomposed from organic nitrogen compounds in those wastewater and wastes. Where in the aqueous solution, ammoniac nitrogen can be classified into ammonium ion $\left[\mathrm{NH}_{4}{ }^{+}\right]$and free ammonia $\left[\mathrm{NH}_{3}(\mathrm{aq})\right]$ which are released from many industrial plants of coke, fertilizers, and metal finishing [2]. Higher concentration of ammonium will cause a sharp decrease of dissolved oxygen and obvious toxicity on aquatic organisms [3]. The amount of ammonium discharged to the environment is regulated strictly, where the maximum limit for drinking water according to the World Health Organization (WHO) is $10 \mathrm{mg} / \mathrm{L}$ of nitrate. Hence, it is of great importance to control nitrogen pollution due to the nitrification process resulting in the formation of nitrites and nitrates which lead to serious illness. Accordingly, the control of ammonia released into the environment is important in the protection of public health.

Several technologies have been employed, including precipitation [4], supercritical water oxidation [5], physicochemical [6], microwave radiation [7], ion exchange [8], and sorption [9]. Sorption of ammonium and some heavy metal ions using various types of natural and their modified clays has been studied and proved to be reliable, feasible, efficient, and less expensive as compared to the commercial activated carbon sorbents [10-15]. Of these clay sorbents investigated, the kaolinite clay gave the highest sorption capacity [14]. The layer structure and the high concentration of surface functional groups such as hydroxyl groups on kaolinite in particular stand behind its high sorption performance [1517]. It has been reported that the sorption properties of kaolinite are related to the nature of its surface, edges, corners, porosity, and the existence of both Bronsted and Lewis acid sites which played an important role in enhancing the sorption capacity of kaolinite towards $\mathrm{Ni}$ and $\mathrm{Cu}$ (II) ions [15]. It has been pointed out that acid activation followed by thermal treatment increases the removal of phosphate to 
a good extent on activated kaolinite [16]. However, to our knowledge, the removal of $\mathrm{NH}_{4}{ }^{+}$ions onto calcined and/or acid-activated kaolinite has not been studied to date.

In the present investigation, the $\mathrm{NH}_{4}{ }^{+}$sorption at $30^{\circ} \mathrm{C}$ was conducted on natural kaolinite and thermally and acidactivated kaolinites. Activation was made either by thermal treatment, acid treatment, or acid treatment of prethermally treated kaolinite. Characterization of the sorbents was determined by XRD, FTIR, SEM, and $\mathrm{N}_{2}$ sorption techniques. The factors controlling $\mathrm{NH}_{4}{ }^{+}$sorption including the solution $\mathrm{pH}$, amount of sorbent dose, and initial $\mathrm{NH}_{4}{ }^{+}$concentration in the solution were considered. The kinetics of sorption were determined by applying pseudo-first-order, pseudosecond-order, Elovich, and intraparticle diffusion models. The equilibrium sorption data were analyzed using Freundlich, Langmuir, and Dubinin-Radushkevich equations.

\section{Materials and Methods}

2.1. Materials. In this work, Egyptian kaolinite clay $(\mathrm{K})$ from El-Tih plateau, Egypt (kindly provided by Sinai Manganese Co.), was used as the starting material. The mineralogy of kaolinite raw was determined by means of a XRF Phillips Powder Spectrometer Model (PW 1170) using Co $\mathrm{K}_{\alpha}$ radiations as published in [18]. It was found that the $\mathrm{K}$ contained 95\% kaolinite with $5 \%$ anatase $\left(\mathrm{TiO}_{2}\right)$. The chemical analysis data are listed in Table 2. The principle aim of this work was to activate natural kaolinite by either acid, heat, or acid leaching thermally pretreated kaolinite, thereby increasing its surface area and changing its physicochemical characteristics. For this purpose, advantage was taken of the methods described by Hassan and El-Shall [18].

For the chemical activation the starting kaolinite (K) was soaked in 50\% (v/v) sulphuric acid (98\% assay, $\left.\mathrm{H}_{2} \mathrm{SO}_{4}\right)$ for $24 \mathrm{~h}$ at room temperature $\left(30^{\circ} \mathrm{C}\right)$ and then activated in a muffle furnace at $886^{\circ} \mathrm{C}$ for $2 \mathrm{~h}$. Thermal activation was accomplished by calcining kaolinite at the same temperature for 2 hours in a muffle furnace to produce metakaolinite. For the acid leaching process, the resulting metakaolinite sample was leached with $50 \%(\mathrm{v} / \mathrm{v}) \mathrm{H}_{2} \mathrm{SO}_{4}$ for $1 \mathrm{~h}$ at $30^{\circ} \mathrm{C}$ and then raised the temperature up to $100^{\circ} \mathrm{C}$ for another $1 \mathrm{~h}$. The treated clays were washed thoroughly with distilled water several times until they are free from $\mathrm{SO}_{4}{ }^{2-}$ and the $\mathrm{pH}$ of the rinsed solution reaches $\sim 6$. The washed samples were centrifuged and then dried overnight at $100^{\circ} \mathrm{C}$ in an air oven until constant weight was attained. These samples were designated as $\mathrm{AHK}, \mathrm{HK}$, and $\mathrm{HAK}$, respectively, where A stands for acid, $\mathrm{H}$ for heat, and $\mathrm{K}$ for kaolinite according to the sequence in preparation procedures.

Ammonium chloride stock $\left(1000 \mathrm{mg} \cdot \mathrm{L}^{-1}\right)$ was prepared by dissolving in deionized water. Synthetic aqueous solutions were employed by adding appropriate amount of $\mathrm{NH}_{4} \mathrm{Cl}$ stock solution to deionized water to obtain $\mathrm{NH}_{4} \mathrm{Cl}$ concentrations in the range of $100-1000 \mathrm{mg} \cdot \mathrm{L}^{-1}$.

2.2. Kaolinite Characterization. Nitrogen sorption isotherms at $-196^{\circ} \mathrm{C}$ were constructed using a Quantachrome Nova Automated Gas Sorption instrument, where the tested
TABLE 1

\begin{tabular}{lc}
\hline Value of $R_{L}$ & Type of isotherm \\
\hline$R_{L}>1$ & Unfavorable \\
$R_{L}=1$ & Linear \\
$0<R_{L}<1$ & Favorable \\
$R_{L}=0$ & Irreversible \\
\hline
\end{tabular}

TABLE 2: Chemical analysis of kaolinite clay as given in literature [18].

\begin{tabular}{lcc}
\hline Oxide & \multicolumn{2}{c}{ Content (wt\%) } \\
& Evaluated & Theoretical \\
\hline $\mathrm{SiO}_{2}$ & 51.51 & 46.3 \\
$\mathrm{Al}_{2} \mathrm{O}_{3}$ & 31.43 & 39.8 \\
$\mathrm{Fe}_{2} \mathrm{O}_{3}$ & 0.35 & $0-0.2$ \\
$\mathrm{TiO}_{2}$ & 2.14 & $0-0.3$ \\
$\mathrm{~K}_{2} \mathrm{O}$ & 0.01 & - \\
$\mathrm{CaO}$ & 1.51 & - \\
$\mathrm{NaO}$ & 0.50 & - \\
$\mathrm{SO}_{3}$ & 0.036 & - \\
$\mathrm{LOI}$ & 13.0 & 13.9 \\
\hline
\end{tabular}

samples outgas at $200^{\circ} \mathrm{C}$ for $2 \mathrm{~h}$. Specific surface areas were calculated by the Brunauer-Emmett-Teller (BET) method. The total pore volume was obtained from the maximum amount of nitrogen gas adsorbed at a relative pressure $P / P^{\circ}=$ 0.999 .

The different types of functional groups were identified by a Fourier transform infrared spectrum (FTIR-6100 JASCO) in the range of $4000-400 \mathrm{~cm}^{-1}$.

The total surface acidity of each sample was determined employing the method proposed by Boehm [19]. Thus, $0.1 \mathrm{~g}$ of each investigated samples was taken and $50 \mathrm{~mL}$ of $0.1 \mathrm{M}$ $\mathrm{NaOH}$ was added to determine the acidity. The mixture was kept at a constant temperature of $30^{\circ} \mathrm{C}$ with constant stirring overnight. Subsequently, a $10 \mathrm{~mL}$ aliquot of each of the solutions in contact with the kaolinite samples was titrated employing corresponding $0.1 \mathrm{M}$ standard solution of $\mathrm{HCl}$.

Surface morphologies of the prepared sorbents were identified using a scanning electron microscope (SEM-JEOL, JXA-840A electron probe microanalyzer, Japan). Before scanning, the selected samples were coated with gold ( $\mathrm{Au}$ ) using a quick autocoater (JFC-1500, JEOL). X-ray diffraction (XRD) measurements of kaolinite sorbents were carried out using Phillips analytical X-ray spectrometer (PW1710) employing $\mathrm{Cu}-\mathrm{K}_{\alpha}$ radiations. This technique was used to determine the structural changes that occurred in the kaolinite clay during thermal and acid treatment processes.

2.3. Sorption of $\mathrm{NH}_{4}^{+}$Ions. Batch sorption experiments were conducted by mixing $0.1 \mathrm{~g}$ of sorbent with $50 \mathrm{~mL}$ of $\mathrm{NH}_{4}^{+}$ solutions at the desired concentration $\left(0.01-0.2 \mathrm{mg} \cdot \mathrm{L}^{-1}\right)$ in a $100 \mathrm{~mL}$ sealed conical flask using a shaking thermostat machine at a speed of $120 \mathrm{rpm} / \mathrm{min}$ for an equilibrium 
time of $2 \mathrm{~h}$ at $30^{\circ} \mathrm{C}$. The effect of solution $\mathrm{pH}$ value on the equilibrium sorption of the $\mathrm{NH}_{4}{ }^{+}$was investigated by mixing $0.1 \mathrm{~g}$ of sorbent with $50 \mathrm{~mL}$ of $\mathrm{NH}_{4}{ }^{+}$solution between $\mathrm{pH}$ values of (5 to $9 \pm 0.05$ ). The effect of sorbent dose on the equilibrium sorption of $\mathrm{NH}_{4}{ }^{+}$is an important parameter since it determines the capacity of sorbate at a given initial concentration of the latter. The effect of the investigated samples dosage on the sorption of $\mathrm{NH}_{4}{ }^{+}$ions was studied employing $0.05,0.1,0.3,0.5$, and $1 \mathrm{~g}$ of samples $\mathrm{K}$, AHK, $\mathrm{HK}$, and HAK in $50 \mathrm{~mL}$ of $\mathrm{NH}_{4}^{+}$solution $\left(C_{0}=262 \mathrm{mg} \cdot \mathrm{L}^{-1}\right)$.

To follow the sorption kinetics, a sample of dried sorbent $(0.5 \mathrm{~g})$ was added to $100 \mathrm{~mL}$ of the aqueous sorbate solution at an initial $\mathrm{pH}$ 7. Different initial sorbate concentrations $\left(C_{0}=100,200\right.$, and $\left.500 \mathrm{mg} \cdot \mathrm{L}^{-1}\right)$ were used for sorbate. The uptake of the sorbate per unit mass of the sorbent was followed by withdrawing a $2 \mathrm{~mL}$ of supernatant at fixed time intervals $(\mathrm{min})$ to determine the concentration at each time, $C_{t}$. The values of both $C_{0}$ and $C_{t}$ were measured spectrophotometrically at a wavelength $\lambda_{\max }=427 \mathrm{~nm}$ (UV-Vis spectrophotometer, Shimadzu model-PC-2401).

Also, equilibrium sorption measurements were carried out at $30^{\circ} \mathrm{C}$ at the optimum $\mathrm{pH}$ 7. Different initial concentrations of the sorbate were used and these solutions were shaken in a thermostat for $24 \mathrm{~h}$ to ensure equilibrium conditions. $2 \mathrm{~mL}$ samples were withdrawn from each sorption flask to determine the equilibrium concentrations. The amount adsorbed at equilibrium, $q_{e}(\mathrm{mg} / \mathrm{g})$, was determined from the corresponding initial concentration using

$$
q_{e}=\frac{\left(C_{0}-C_{e}\right) V}{W},
$$

where $C_{0}$ and $C_{e}$ are the initial and equilibrium liquid phase concentrations of $\mathrm{NH}_{4}{ }^{+}$solution $\left(\mathrm{mg} \cdot \mathrm{L}^{-1}\right)$, respectively, $V$ the volume of the solution (L), and $W$ is the weight of the dry investigated sample used (g).

\section{Results and Discussions}

3.1. Physicochemical Features of the Kaolinite Sorbents. The textural properties (surface area and porosity) of a sorbent are important parameters $[20,21]$ in determining its sorption capacity as well as its sorption performance. The nitrogen sorption isotherms thus obtained (not illustrated) were analyzed using the conventional BET equation. Table 3 lists the surface area, total pore volume, mean pore diameter, and total acidity of natural and activated kaolinite samples. In Table 3 , the results reveal that (i) activation with sulphuric acid $(50 \% \mathrm{v} / \mathrm{v})$ brought about a $100 \%$ increase in specific surface area, a 2.44 -fold increase in total pore volume, a $17 \%$ increase in pore diameter, and about a $10 \%$ decrease in the total acidity; (ii) calcination of $\mathrm{K}$ at $886^{\circ} \mathrm{C}$ for $2 \mathrm{~h}$ was associated with a $27 \%$ decrease in the specific surface area, $21 \%$ decrease in the total pore volume, $9 \%$ increase in pore diameter, and about 20\% decrease in the total acidity; (iii) concerning calcination followed by leaching with $\mathrm{H}_{2} \mathrm{SO}_{4}$, the changes were determined to be a 2.94 -fold increase in specific surface area, $\approx$ a 2.5 -fold increase in the total pore volume, a $26 \%$ decrease in the mean pore diameter, and a $41 \%$ decrease in the total acidity. It may be concluded that leaching process involves partial dissolution and reprecipitation of amorphous $\mathrm{Si}$ and $\mathrm{Al}$ materials besides the removal of other metallic oxides leaving pores within the structure and thus leading to a remarkable increase in both specific surface area and total pore volume as well as a decrease in average pore diameter (cf. Table 3). This observation was confirmed by FTIR spectra.

The chemistry of the surface, in particular, that of the surface functional groups, plays an important role in determining the sorption capacities of the investigated kaolinites for $\mathrm{NH}_{4}{ }^{+}$. FTIR spectra were recorded over the spectral region $4000-400 \mathrm{~cm}^{-1}$ for all the kaolinites prepared. The FTIR plots (not illustrated) were used to identify the surface functional groups and results can be broadly described as follows. (i) The FTIR spectrum of natural kaolinite (K) shows bands located at 3695,3651 , and $3620 \mathrm{~cm}^{-1}$ which ascribed to disordered poorly crystalline kaolinite clay. (ii) After thermal and acid treatments, the bands at wavenumber higher than $3600 \mathrm{~cm}^{-1}$ disappeared in cases of HK, HAK, and AHK samples. (iii) Acid treatment of kaolinite led to appearance of a new band at $936-905 \mathrm{~cm}^{-1}$ assigned to the Si-O stretching vibration of $\mathrm{Si}-\mathrm{OH}$ group [22]. It is then recognized that acid treatment transforms $\mathrm{Si}-\mathrm{O}$ bands to $\mathrm{Si}-\mathrm{OH}$ bands [23] (iv) The presence of a band at $795-803 \mathrm{~cm}^{-1}$ is generally considered as evidence for a three-dimensional amorphous silica $[18,24,25]$, suggesting the formation of a porous silica with a three-dimensional of cross-linked structure in AHK sample. These findings are in agreement with the results reported earlier by Hassan and El-Shall [18].

The scanning electron micrographs are shown in Figure 1. The micrograph of natural kaolinite $(\mathrm{K})$ shows developed micropores and small particle size of the solid. The micrograph of the thermally treated kaolinite (HK) shows less micropore volume but larger particle size compared with $\mathrm{K}$; this may be ascribed to a sintering process leading to agglomeration of the particles and meanwhile a decrease in the surface area associated with some increase in pore diameter. The micrograph of $\mathrm{H}_{2} \mathrm{SO}_{4}$-activated kaolinite (AHK) depicts a considerable area of black color which may be attributed to the dissolution of relatively large amount of soluble components that may form a dark film leading in turn to masking a fraction of porosity within kaolinite particles. The micrograph of HAK shows more porosity and pore grain particles compared with HK.

Furthermore, X-ray diffraction patterns (XRD) for kaolinite and its activated samples were determined (not shown here). For kaolinite, XRD profile showed well-defined reflections at $2 \theta$ values of $12.41^{\circ}$ and $24.89^{\circ}$ corresponding to $d$ space values of 7.13 and $3.58 \AA$, respectively, which are typically characteristic peaks of kaolinite $1 \mathrm{~A}\left[\mathrm{Al}_{2} \mathrm{Si}_{2} \mathrm{O}_{5}(\mathrm{OH})_{4}\right]$. Also some quartz $\left(\mathrm{SiO}_{2}\right)$ and anatase $\left(\mathrm{TiO}_{2}\right)$ minerals were determined at $2 \theta$ values of $26.64^{\circ}$ and $25.35^{\circ}$, respectively, which remained in all samples, thereby demonstrating their stability among the thermal or acid treatment. It was shown that a wide band at $2 \theta$ range $20-25^{\circ}$ was recorded in the XRD patterns of metakaolinite sample (HK) which ascribed to amorphous silica with a three-dimensional cross-linked structure [17] as confirmed by FTIR. 
TABLE 3: Surface properties of natural and modified kaolinites.

\begin{tabular}{lcccc}
\hline Samples & $\begin{array}{c}S_{\mathrm{BET}} \\
\left(\mathrm{m}^{2} \cdot \mathrm{g}^{-1}\right)\end{array}$ & $\begin{array}{c}\text { Total pore volume } \\
\left(\mathrm{cm}^{3} \cdot \mathrm{g}^{-1}\right)\end{array}$ & $\begin{array}{c}\text { Average pore diameter } \\
(\mathrm{nm})\end{array}$ & $\begin{array}{c}\text { Total acidity } \\
\left(\mathrm{m} \cdot \mathrm{equiv} \cdot \mathrm{g}^{-1}\right)\end{array}$ \\
\hline K & 19.1 & 0.0075 & 15.65 & 5.1 \\
AHK & 39.9 & 0.0183 & 18.36 & 5.3 \\
HK & 13.9 & 0.0059 & 16.97 & 4.9 \\
HAK & 56.09 & 0.0171 & 12.23 & 3.0 \\
\hline
\end{tabular}

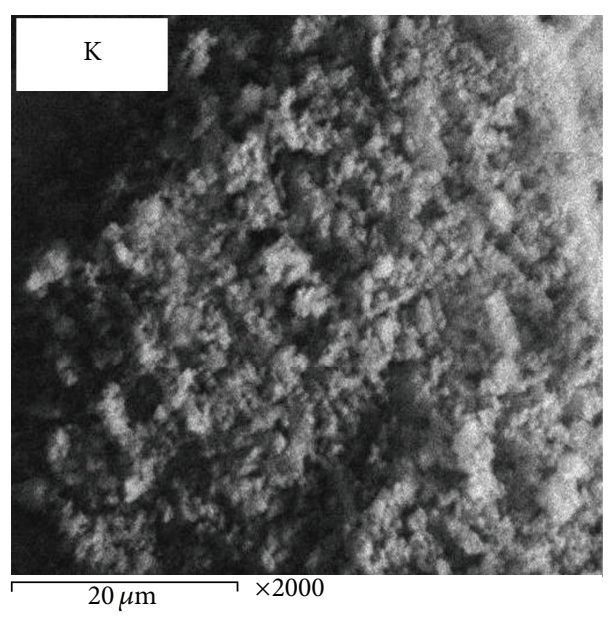

(a)

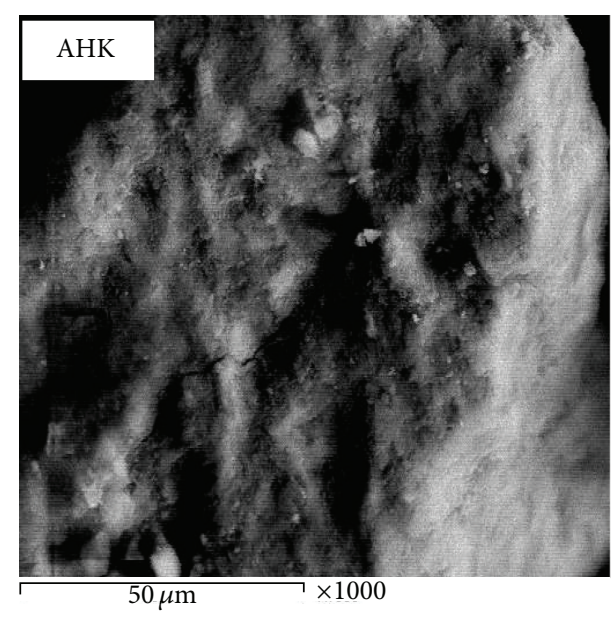

(c)

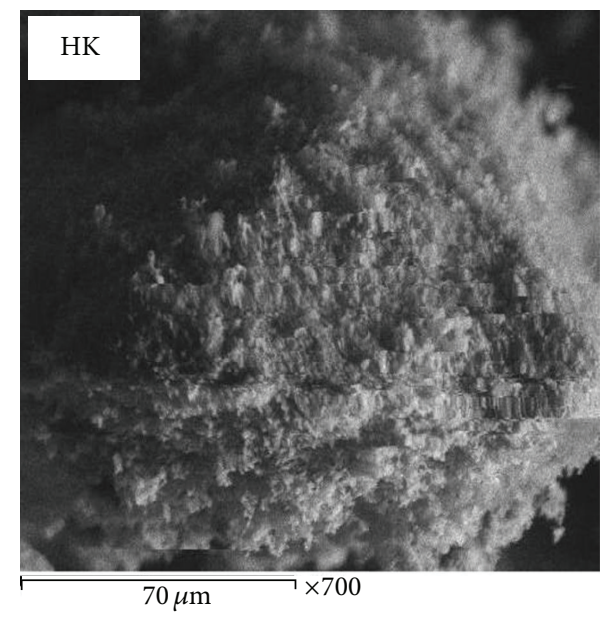

(b)

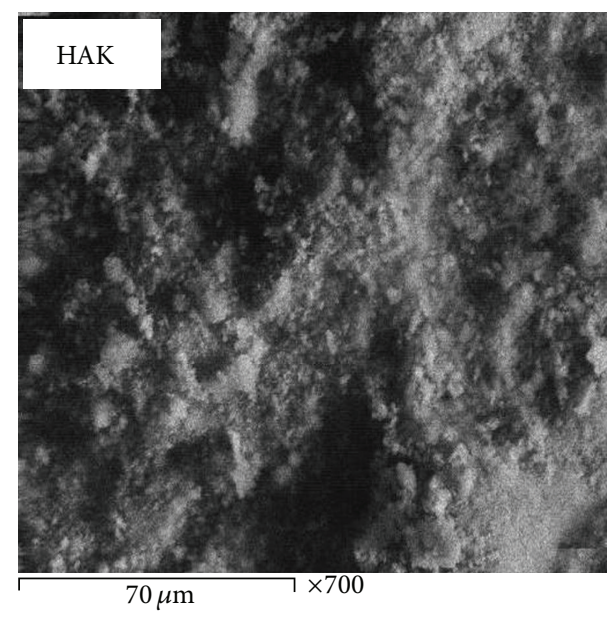

(d)

FIGURE 1: SEM photographs of the natural and modified kaolinite clays.

\subsection{Sorption of $\mathrm{NH}_{4}^{+}$Ions}

3.2.1. Effect of $\mathrm{pH}$. The effect of $\mathrm{pH}$ on the sorption of $\mathrm{NH}_{4}^{+}$ ions from aqueous solution onto investigated samples was studied at pH 5-9 (Figure 2). For all sorbents, the maximum $\mathrm{NH}_{4}{ }^{+}$uptake occurred at $\mathrm{pH}$ 7. However, as $\mathrm{pH}$ increased to alkaline values, the sorption capacity decreased slightly. Solution $\mathrm{pH}$ affected equilibrium between the soluble $\mathrm{NH}_{4}{ }^{+}$ions and dissolved molecular ammonia $\left(\mathrm{NH}_{3}\right)$ in water [26]. In an acidic environment, ammonium was present as $\mathrm{NH}_{4}{ }^{+}[13]$.
The solution $\mathrm{H}^{+}$competed with $\mathrm{NH}_{4}{ }^{+}$to absorb on the kaolinites, so that the sorption of $\mathrm{NH}_{4}{ }^{+}$ions on sorbents decreased. When the $\mathrm{pH}$ increased to alkaline values, the nonvolatile $\mathrm{NH}_{4}{ }^{+}$ion paired with $\mathrm{OH}^{-}$in the solution, which led to the formation of molecular ammonia. As the number of exchangeable ions in the interlayer increased, the removal of ammonium increased. Thus the $\mathrm{NH}_{4}{ }^{+}$sorption was most favorable at neutral $\mathrm{pH}$; for this reason, subsequent experiments were conducted on solutions with an initial $\mathrm{pH} 7$. 


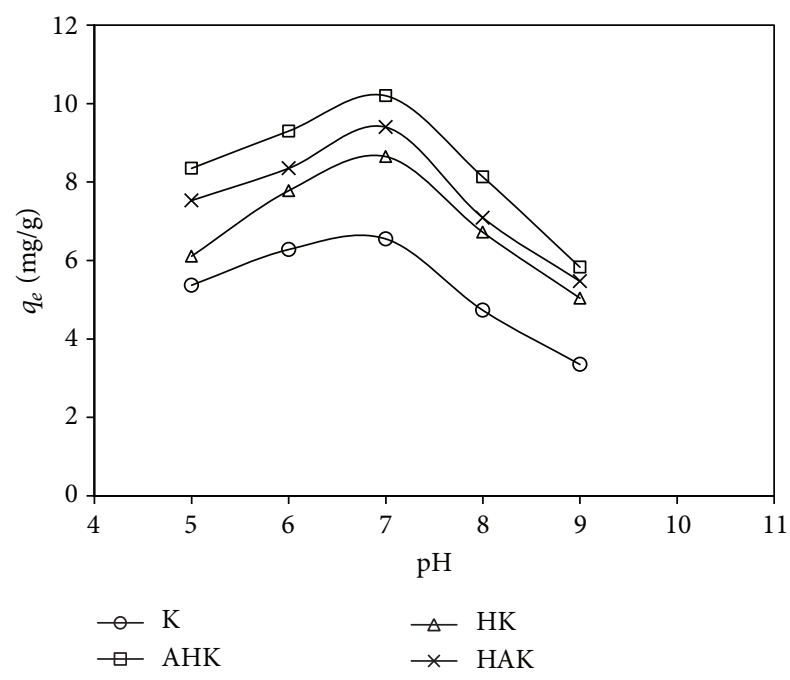

FIgURE 2: Influence of $\mathrm{pH}$ on the amount of $\mathrm{NH}_{4}{ }^{+}$adsorbed onto all investigated sorbents $\left(C_{0}=262 \mathrm{mg} / \mathrm{L}\right.$; sorbent dose $=0.1 \mathrm{~g}$; temperature $=30^{\circ} \mathrm{C}$; contact time $=2 \mathrm{~h}$ ).

3.2.2. Effect of Sorbent Dosage. The sorbent dosage is an important parameter, since it determines the capacity of a sorbate at a given initial concentration of the latter. The effect of $\mathrm{K}, \mathrm{HK}, \mathrm{HAK}$, and AHK dosage $(0.05,0.1,0.3,0.5$, and $1 \mathrm{~g})$ on the sorption of $\mathrm{NH}_{4}{ }^{+}$ions was studied employing at $50 \mathrm{~mL}$ of $\mathrm{NH}_{4}{ }^{+}$solutions $\left(262 \mathrm{mg} \cdot \mathrm{L}^{-1}\right)$. The $\mathrm{NH}_{4}{ }^{+}$sorption was found to decrease as the amount of employed sorbent increased above $0.1 \mathrm{~g}$ as shown in Figure 3. The maximum sorption of $\mathrm{NH}_{4}{ }^{+}$occurred for suspension densities of $0.1 \mathrm{~g}$ per $50 \mathrm{~mL}$ of $\mathrm{NH}_{4}{ }^{+}$solution by $\mathrm{K}, \mathrm{HK}, \mathrm{HAK}$, and $\mathrm{AHK}$ which were found to be $5.21,12.61,10.91$, and $11.75 \mathrm{mg}$, respectively. For this reason, the optimum sorbent dosage was maintained at $0.1 \mathrm{~g}$ for further experiments.

3.2.3. Kinetics of Sorption. The kinetics of sorption process are largely dependent on the physical and/or chemical characteristics of both the sorbent and sorbate [26-29]. The controlling mechanism in the sorption of the $\mathrm{NH}_{4}^{+}$ ions with three different initial concentrations at $30^{\circ} \mathrm{C}$ was examined using various kinetic models such as pseudofirst-order equation (2), pseudo-second-order equation (3), Elovich model equation (4), and intraparticle diffusion model equation (5) to determine whether processes such as mass transfer and/or chemical reaction were evolved:

$$
\begin{gathered}
\log \left(q_{e}-q_{t}\right)=\log q_{e}-\frac{k_{1} t}{2.303} \\
\frac{t}{q_{t}}=\frac{1}{k_{2} q_{e}{ }^{2}}+\frac{t}{q_{e}},
\end{gathered}
$$

where $q_{e}$ and $q_{t}$ are the amounts of solute adsorbed at equilibrium and at a time $\mathrm{mg} / \mathrm{g}$, respectively, $k_{1}$ is the pseudofirst-order sorption rate constant $\left(\mathrm{min}^{-1}\right)$, and $k_{2}$ is the pseudo-second-order sorption rate constant $\left(\mathrm{g} \cdot \mathrm{mg}^{-1} \mathrm{~min}^{-1}\right)$.

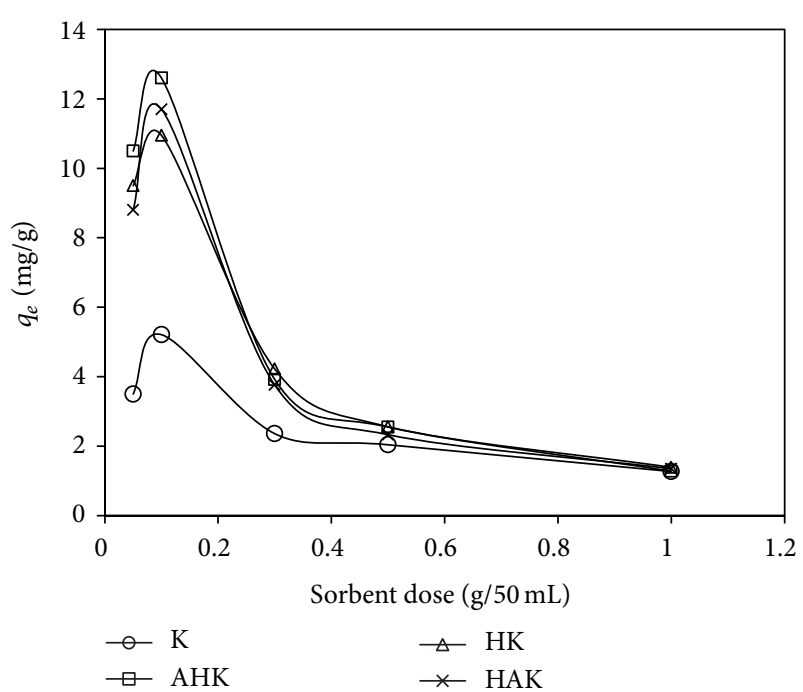

FIGURE 3: Influence of sorbent dose on the sorption of $\mathrm{NH}_{4}{ }^{+}$ions $\left(C_{0}=262 \mathrm{mg} / \mathrm{L} ; \mathrm{pH}=7\right.$; temperature $=30^{\circ} \mathrm{C}$; contact time $\left.=2 \mathrm{~h}\right)$.

In a further attempt to study the nature of sorption, another equation, namely, Elovich equation, normally applicable to chemisorption on energetically heterogeneous solid surface, is given by [28]

$$
q_{t}=\beta \ln (\alpha \beta)+\beta \ln t
$$

where $\alpha$ and $\beta$, respectively, are the initial sorption rate $\left(\mathrm{mg} \cdot \mathrm{g}^{-1} \mathrm{~min}^{-1}\right)$ and the desorption coefficient $\left(\mathrm{g} \cdot \mathrm{mg}^{-1}\right)$, respectively. These can be computed from plots of $q_{t}$ versus $\ln t$.

If intraparticle diffusion is assumed to be the rate-limiting step in the sorption process, the Weber and Morris equation [29] is as follows:

$$
q_{t}=k_{\mathrm{id}} t^{0.5}+C_{i}
$$

where $k_{\text {id }}$ is the intraparticle diffusion constant $\left(\mathrm{g} \cdot \mathrm{mg}^{-1}\right.$ $\min ^{-0.5}$ ) and $q_{t}$ and $t$ have been previously identified, while $C_{i}$ is the intercept at stage $i$.

The kinetic sorption curves at $30^{\circ} \mathrm{C}$ for $\mathrm{NH}_{4}{ }^{+}$ions were obtained with three different initial concentrations $\left(C_{0}=\right.$ 100,200 , and $\left.500 \mathrm{mg} \cdot \mathrm{L}^{-1}\right)$. Figure 4 shows the influence of the time on the sorption of $\mathrm{NH}_{4}{ }^{+}$ions onto $\mathrm{K}, \mathrm{HK}, \mathrm{HAK}$, and AHK. Figure 4 depicts the following. (i) Generally, the amount adsorbed increased typically with the increase of the initial concentration. (ii) All the kinetic data show a tendency to exhibit a plateau. (iii) With the exception of natural kaolinite $(\mathrm{K})$, the other modified kaolinites exhibited their plateau within 10 to $20 \mathrm{~min}$. Initial sorption took place on the most active sites and accordingly the earlier attainment of the kinetic plateau should be expected with sorbents rich in high activated sites for the sorbate under investigation. This may be taken as evidence that thermal treatment and/or leaching with $\mathrm{H}_{2} \mathrm{SO}_{4}$ increased the concentration of highly activated sorption sites for $\mathrm{NH}_{4}{ }^{+}$ions.

All kinetic parameters arising from the application of the four kinetic models to the $\mathrm{NH}_{4}{ }^{+}$sorption onto $\mathrm{K}$, 

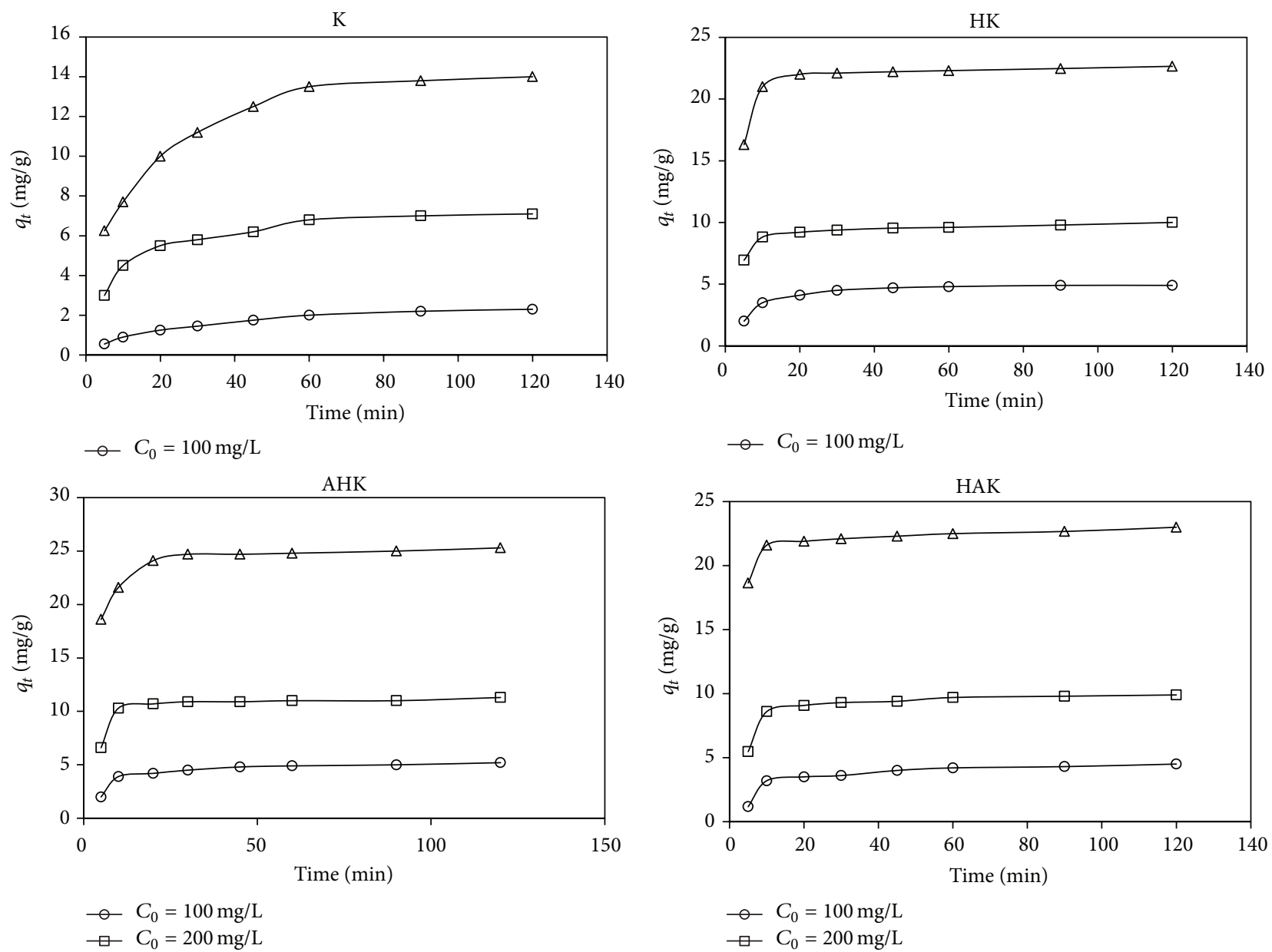

(a)

(b)

FIGURE 4: Influence of contact time on the sorption of $\mathrm{NH}_{4}{ }^{+}$onto all investigated sorbents (sorbent dose $=0.1 \mathrm{~g} ; \mathrm{pH}=7$; temperature $=30^{\circ} \mathrm{C}$; contact time $=2 \mathrm{~h}$ ).

HK, HAK, and AHK sorbents as well as the correlation coefficient values $\left(R^{2}\right)$ are listed in Table 4 . The pseudo-firstorder kinetic equation was applied by plotting $\log \left(q_{e}-q_{t}\right)$ versus $t$ (not shown). No satisfactory straight lines were obtained, indicating that the sorption of $\mathrm{NH}_{4}{ }^{+}$ions onto the investigated samples does not follow the pseudo-first-order kinetic. On the other hand, the application of pseudo-secondorder rate equation was found to be satisfactorily applicable to the sorption data in Figure 5, giving straight lines with high values of $R^{2}$ ranging between 0.9947 and 0.9980 . The linear plots of this kinetic model are linear without scatter of points. Another evidence for the reliability of this model is the agreement of the calculated $\left(q_{e, \mathrm{cal}}\right)$ and the corresponding experimental values $\left(q_{e \text {,exp }}\right)$, indicating the dependence of the sorption rate on both the sorbent and sorbate concentrations.

The Elovich equation was also applied to suggest the type of sorption [28]. Two representative Elovich plots of $\mathrm{NH}_{4}{ }^{+}$sorption are shown in Figure 6. The values of $\alpha$ and $\beta$ and the corresponding $R^{2}$ are listed in Table 4 . Evidently the Elovich plots are linear with high values of $R^{2}$. The initial rate of sorption $(\alpha)$ generally increases with the increase in $\mathrm{NH}_{4}{ }^{+}$concentration. Thus, for example, the value of $\alpha$ at initial concentration of $\mathrm{NH}_{4}{ }^{+}\left(100 \mathrm{mg} \cdot \mathrm{L}^{-1}\right)$ adsorbed on $\mathrm{HK}$ was 196.4 , the increase to $200 \mathrm{mg} \cdot \mathrm{L}^{-1}$ brought about a tremendous increase in $\alpha$ to $17.3 \times 10^{4}$, and the increase of $\mathrm{NH}_{4}{ }^{+}$concentration to $500 \mathrm{mg} \cdot \mathrm{L}^{-1}$ was associated again with further increase in $\alpha$ to $30.3 \times 10^{5}$. On the other hand, the corresponding desorption rate coefficient values ( $\beta)$ are moderate and decrease with the increase in $\mathrm{NH}_{4}{ }^{+}$ concentration. This indicates that $\mathrm{NH}_{4}{ }^{+}$ions were held at energetically nonuniform sites, and perhaps at chemically different sites.

The uptake of sorbate species by sorbents is usually limited by intraparticle diffusion. To determine if intraparticle diffusion was the rate-determining step for sorption, the data in Figure 4 for HK and HAK samples were replotted against the square root of time as suggested by Weber and Morris [29]. Plots of $q_{t}$ as a function of $t^{1 / 2}$ at different concentrations of solution are shown in Figure 7.

The plots exhibit two linear ranges, which indicate that the sorption rate is controlled by two processes. The first step is related to the diffusion of $\mathrm{NH}_{4}{ }^{+}$towards the sorbent and 


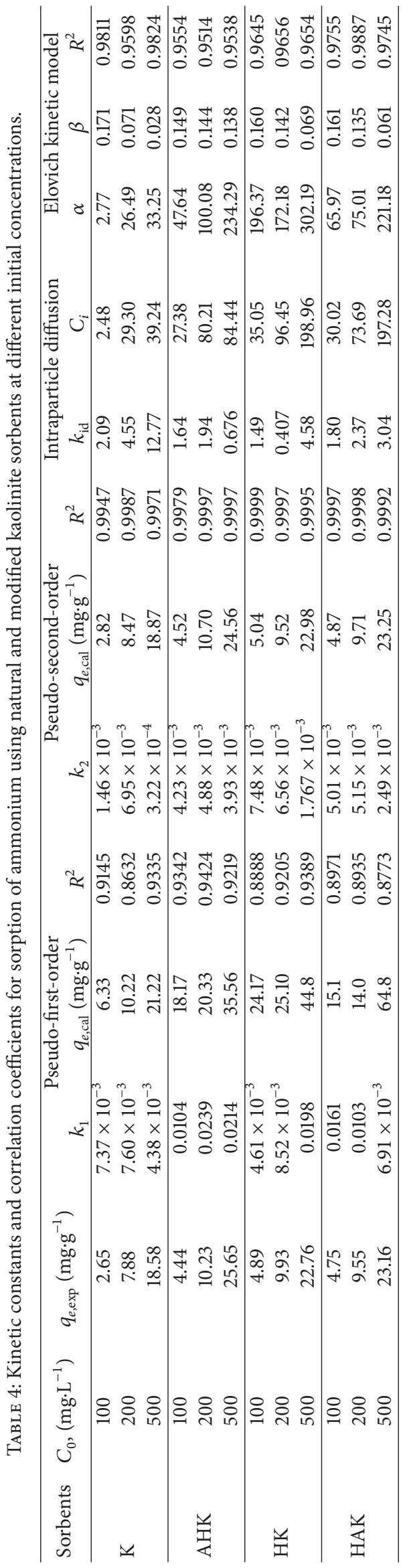



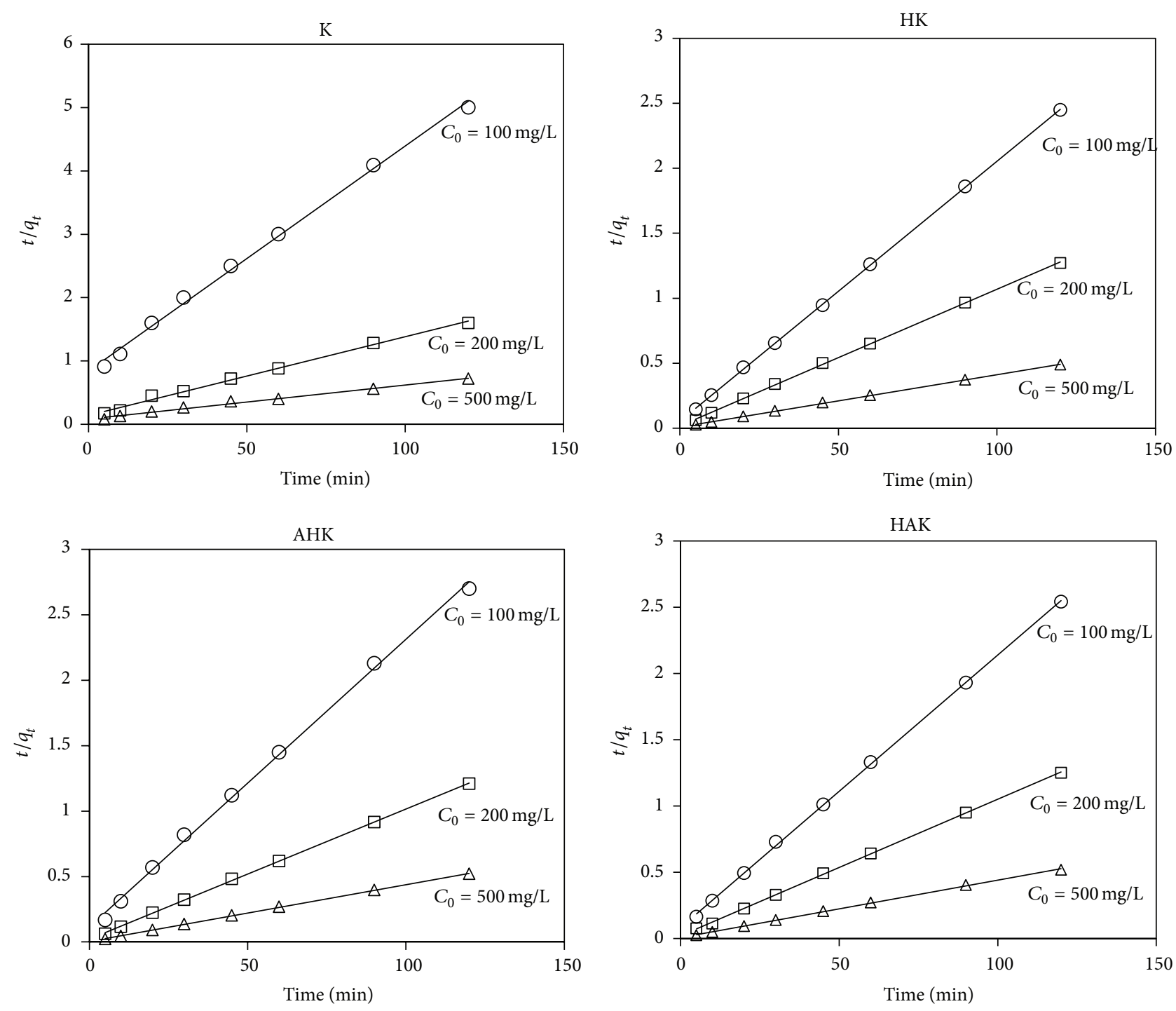

(a)

(b)

FIGURE 5: Pseudo-second-order kinetic plots for the sorption of $\mathrm{NH}_{4}{ }^{+}$onto all investigated sorbents at different initial concentrations (sorbent dose $=0.1 \mathrm{~g} ; \mathrm{pH}=7$; temperature $=30^{\circ} \mathrm{C}$; contact time $=2 \mathrm{~h}$ ).

is the fastest step where the majority of the $\mathrm{NH}_{4}{ }^{+}$ions can be sorbed. This is followed by the second step, which consists of intraparticle diffusion [30]. From the linear corresponding to the second step of data presented in Figure 7, the obtained $K_{\text {id }}$ values increase with increasing solution concentration, which indicates that the contribution of intraparticle diffusion to the sorption process is less significant as the amount of $\mathrm{NH}_{4}{ }^{+}$ ions available for sorption increases. These results obtained indicate the applicability of the pseudo-second-order, Elovich equation, and intraparticle diffusion to the present sorption system.

3.2.4. Sorption Isotherm Models. The Langmuir, Freundlich, and Dubinin-Radushkevich (D-R) isotherm models were employed for fitting the experimental data [31-33]. The Langmuir model employs the assumption that the surface of the sorbent is totally homogeneous, whereas the Freundlich isotherm is suitable for a highly heterogeneous surface. The D-R isotherm, on the other hand, is based on the potential theory of sorption which assumes that the surface is energetically nonuniform and that the dominant sorption interaction involves dispersion forces. The linear form of the Langmuir isotherms is given as

$$
\frac{C_{e}}{q_{e}}=\frac{1}{K_{L} q_{m}}+\frac{1}{q_{m}} C_{e}
$$

where $q_{m}$ is the maximum amount adsorbed which is assumed to be the monolayer sorption capacity, both expressed in $\left(\mathrm{mg} \cdot \mathrm{g}^{-1}\right)$, and $K_{L}$ is the Langmuir constant $\left(\mathrm{mg} \cdot \mathrm{L}^{-1}\right)$ related to the free energy of sorption as expressed in $\left(K_{L} \alpha e^{-\Delta G / R T}\right)$. Thus the free energy of sorption $\Delta G\left(\mathrm{~kJ} \cdot \mathrm{mol}^{-1}\right)$ 


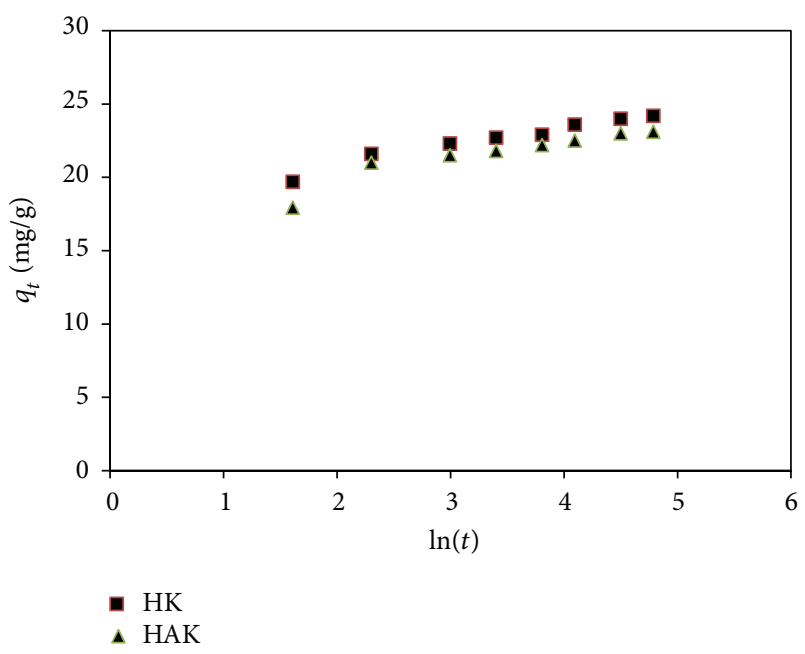

FIGURE 6: Elovich kinetic plots for the sorption of $\mathrm{NH}_{4}{ }^{+}$by $\mathrm{HK}$ and HAK sorbents $\left(C=50 \mathrm{mg} \cdot \mathrm{L}^{-1}\right.$; sorbent dose $=0.1 \mathrm{~g} ; \mathrm{pH}=7$; temperature $=30^{\circ} \mathrm{C}$; contact time $=2 \mathrm{~h}$ ).

can also be evaluated from the parameter $K_{L}$ according to the expression $\Delta G=-R T \ln K_{L}$.

The linear form of the Freundlich equation is given as

$$
\ln q_{e}=\ln K_{F}+\frac{1}{n} \ln C_{e}
$$

where $K_{F}$ is the Freundlich constant related to the sorption capacity, in which $1 / n$ is a constant related to the sorption strength, that is, the sorbent-sorbate interaction.

Another independent model was also applied to the equilibrium sorption data of $\mathrm{NH}_{4}{ }^{+}$ions onto the investigated samples. This model is adopted by Dubinin-Radushkevich where it assumes that only a small fraction of the surface is uniform in structure and energetically homogeneous. The D$\mathrm{R}$ equation is given as

$$
q_{e}=q_{\mathrm{DR}} e^{-\beta \varepsilon^{2}}
$$

where $q_{\mathrm{DR}}$ is the monolayer sorption capacity $\left(\mathrm{mg} \cdot \mathrm{g}^{-1}\right), \beta$ is the constant related to the mean sorption energy $\left(\mathrm{g}^{2} \cdot \mathrm{J}^{-2}\right)$, and $\varepsilon$ is the Polanyi potential energy of the surface $\left(\mathrm{J}^{2} \cdot \mathrm{g}^{-2}\right)$ which equal $R T \ln \left(1+1 / C_{e}\right)$, where $R$ is the universal gas constant $\left(8.314 \mathrm{~kJ} \cdot \mathrm{mol}^{-1} \cdot \mathrm{K}^{-1}\right)$ and $T$ is the absolute temperature $(\mathrm{K})$.

The linear form of $\mathrm{D}-\mathrm{R}$ equation can be written as

$$
\ln q_{e}=\ln q_{\mathrm{DR}}-\beta \varepsilon^{2} .
$$

A plot of $\ln q_{e}$ versus $\varepsilon^{2}$ values gave a straight line. The values of $q_{\mathrm{DR}}$ and $\beta$ were obtained from the intercept and slope, respectively. The sorption energy $E_{a}\left(\mathrm{~kJ} \cdot \mathrm{mol}^{-1}\right)$ can be obtained from the relationship:

$$
E_{a}=\frac{1}{\sqrt{-2 \beta}} .
$$

The equilibrium sorption isotherms of $\mathrm{NH}_{4}{ }^{+}$ions at $30^{\circ} \mathrm{C}$ onto all investigated samples are shown in Figure 8. A contact time of $24 \mathrm{~h}$ was allowed to ensure equilibrium condition. The sorption isotherms of $\mathrm{NH}_{4}{ }^{+}$ions onto kaolinites exhibit very initial steep portion followed by a plateau covering a wide range of equilibrium concentrations. These isotherms are typical type $L$ isotherms according to the classification reported by Ho [34].

The essential characteristics of the Langmuir isotherm can be expressed in terms of a dimensionless constant separation factor of equilibrium parameters $R_{L}$, which describes the type of isotherm and is defined by the following relationship: $R_{L}=1 /\left(1+K_{L} C_{0}\right)$. The parameter $R_{L}$ gives an indication of the isotherm type. Here, the magnitude of $R_{L}$ is a reflection of the isotherm shape, according to Table 1.

The values of $R_{L}$ for the sorption isotherms of $\mathrm{NH}_{4}{ }^{+}$ions at $30^{\circ} \mathrm{C}$ were calculated. All the $R_{L}$ values are greater than 0 and less than 1 , indicating the favorability of the sorption of the investigated pollutant by the investigated sorbents.

The Langmuir, Freundlich, and D-R isotherm parameters evaluated from the corresponding isotherms with their correlation coefficients are listed in Table 5. Inspection of Table 5 indicates that (i) comparing the correlation coefficient value of the linear plot of the Langmuir, Freundlich, and $\mathrm{D}-\mathrm{R}$ isotherms indicated that the Langmuir model gave a better statistical fit, (ii) from Langmuir isotherm model, the calculated sorption monolayer capacity $\left(q_{m}, \mathrm{mg} \cdot \mathrm{g}^{-1}\right)$ of all investigated samples for $\mathrm{NH}_{4}{ }^{+}$ions at $30^{\circ} \mathrm{C}$ decreased in the following order: $\mathrm{AHK}>\mathrm{HAK}>\mathrm{HK}>\mathrm{K}$, (iii) the negative value of $\Delta G$ indicates the feasibility and spontaneous nature of the sorption of $\mathrm{NH}_{4}{ }^{+}$ions onto the investigated samples. The fact that the $\Delta G$ values were larger than $-22 \mathrm{~kJ} \cdot \mathrm{mol}^{-1}$ also shows that the sorption was a physical process [35], and (iv) for D-R sorption isotherm model, the sorption energies of the investigated samples were between 1.183 and $1.357 \mathrm{~kJ} \cdot \mathrm{mol}^{-1}$. The sorption energy values provide information about the sorption mechanism, that is, whether it involves ion exchange or physical sorption. Thus, if the value of sorption energy is between 8 and $16 \mathrm{~kJ} \cdot \mathrm{mol}^{-1}$, the sorption process corresponds to ion exchange process. The sorption energy values obtained in the present study were less than those expected for a typical ion exchange process, thereby suggesting that the sorption mechanism may be a combination of electrostatic and physical sorption. At the start of the sorption process (i.e., during the formation of a monolayer), ion exchange and van der Waals interactions are predominantly responsible for the process.

The maximum sorption capacities $\left(q_{m}, \mathrm{mg} \cdot \mathrm{g}^{-1}\right)$ for $\mathrm{NH}_{4}{ }^{+}$ ions by the present kaolinites were compared with those by other clay sorbents reported in the literature. It was found that the prepared kaolinite showed higher sorption of $\mathrm{NH}_{4}{ }^{+}$than that adsorbed by other clays as follows: $10.87-45.45 \mathrm{mg} \cdot \mathrm{g}^{-1}$ in this study, $8.61 \mathrm{mg} \cdot \mathrm{g}^{-1}$ —zeolite $13 \mathrm{X}$ [10], $9.21 \mathrm{mg} \cdot \mathrm{g}^{-1}$ —natural clynoptilolite [11], $17.3 \mathrm{mg} \cdot \mathrm{g}^{-1}-\mathrm{NaCl}$ modified zeolite [13], and $30.1 \mathrm{mg} \cdot \mathrm{g}^{-1}$-natural Turkish bentonite [14]. Thus, the physical, chemical, and acid-leached of thermal treatments caused a remarkable increase in the sorption capacity of 


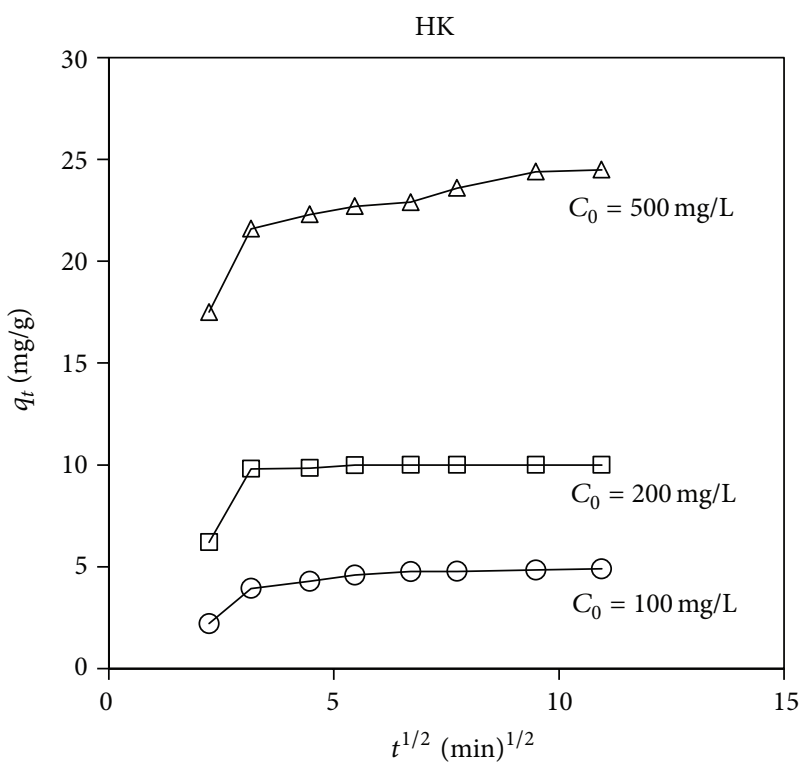

(a)

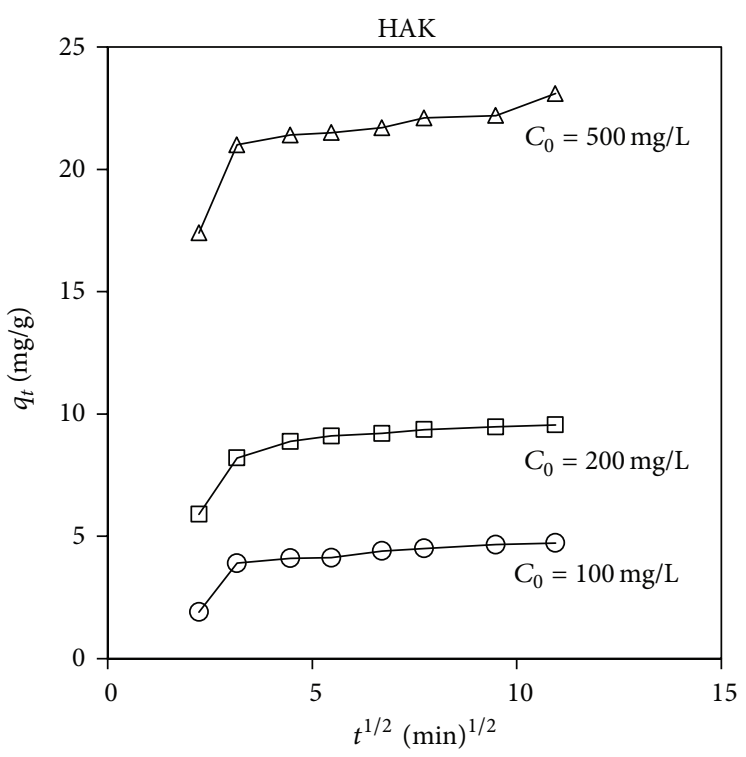

(b)

FIGURE 7: Intraparticle diffusion plots for the sorption of $\mathrm{NH}_{4}{ }^{+}$by $\mathrm{HK}$ and $\mathrm{HAK}$ sorbents (sorbent dose $=0.1 \mathrm{~g} ; \mathrm{pH}=7$; temperature $=30^{\circ} \mathrm{C}$; contact time $=2 \mathrm{~h}$ ).

TABLE 5: Langmuir, Freundlich, and D-R isotherm parameters for sorption of $\mathrm{NH}_{4}{ }^{+}$ions onto natural and modified kaolinites.

\begin{tabular}{lcccc}
\hline Isotherm parameters & $\mathrm{K}$ & AHK & HK & HAK \\
\hline Langmuir isotherm & & & & \\
$q_{m}\left(\mathrm{mg} \cdot \mathrm{g}^{-1}\right)$ & 10.87 & 45.45 & 38.46 & 43.48 \\
$K_{L}\left(\mathrm{~L} \cdot \mathrm{g}^{-1}\right)$ & 0.7022 & 0.3107 & 0.2962 & 0.2949 \\
$R_{L}$ & 0.1246 & 0.2435 & 0.2524 & 0.2532 \\
$\Delta G\left(\mathrm{~kJ} \cdot \mathrm{mol}^{-1}\right)$ & -24.7 & -22.7 & -22.5 & -22.5 \\
$R^{2}$ & 0.9749 & 0.9750 & 0.9595 & 0.9622 \\
Freundlich isotherm & & & & \\
$K_{F}(\mathrm{mg} / \mathrm{g}) \cdot(\mathrm{L} / \mathrm{mg})^{-1 / n}$ & 1.851 & 8.367 & 3.823 & 6.005 \\
$1 / n$ & 0.5959 & 0.5982 & 0.5550 & 0.8171 \\
$R^{2}$ & 0.9367 & 0.9548 & 0.9499 & 0.9595 \\
$\mathrm{D}-\mathrm{R}$ isotherm & & & & \\
$q_{\mathrm{DR}}\left(\mathrm{mg} \cdot \mathrm{g}^{-1}\right)$ & 7.81 & 18.05 & 16.85 & 17.61 \\
$\beta \times 10^{-3}\left(\mathrm{~mol}^{2} \cdot \mathrm{kJ}^{-2}\right)$ & -2.266 & -1.723 & -1.064 & -1.817 \\
$E_{a}\left(\mathrm{~kJ} \cdot \mathrm{mol}^{-1}\right)$ & 1.183 & 1.357 & 1.221 & 1.321 \\
$R^{2}$ & 0.9353 & 0.8909 & 0.7178 & 0.7878 \\
\hline
\end{tabular}

kaolinite clay confirming the amenability of treatment in removing ammonium from wastewater.

\section{Conclusion}

The sorption studies of $\mathrm{NH}_{4}{ }^{+}$onto the ore kaolinite and its activated samples may be considered to be a spontaneous and exothermic process, as indicated by negative values obtained for $\Delta G$. FTIR analysis showed that the surface

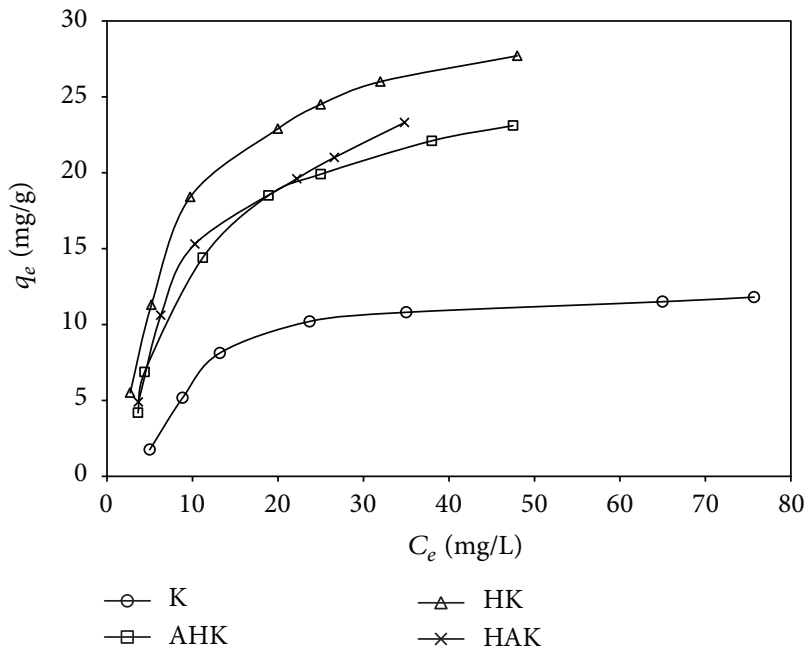

FIGURE 8: Sorption isotherms for $\mathrm{NH}_{4}^{+}$ions by all investigated sorbents (sorbent dose $=0.1 \mathrm{~g} ; \mathrm{pH}=7$; temperature $=30^{\circ} \mathrm{C}$; contact time $=24 \mathrm{~h}$ ).

of the resulting sorbents was occupied by $-\mathrm{OH}$ functional groups. The sorption isotherms of $\mathrm{NH}_{4}{ }^{+}$ions onto investigated kaolinites exhibit very initial steep portion followed by a plateau covering a wide range of equilibrium concentrations. The initial interactions might be with the surface sites, but then the ammonium ions slowly enter into the pores, slowing down the entire process. The pseudo-second-kinetic-order and Langmuir isotherm models best describe the sorption of $\mathrm{NH}_{4}{ }^{+}$ions. Elovich and Dubinin-Radushkevich parameters 
refer to physical sorption. The activation of kaolinite clay thermally or chemically increases its capacity almost fourfold toward $\mathrm{NH}_{4}{ }^{+}$as shown in the subsequent order: $\mathrm{K}>\mathrm{HK}$ $>\mathrm{HAK}>\mathrm{AHK}$. Thus the modification of natural kaolinite brings remarkable surface properties and sorption capacities. Therefore, obtained results showed that given treatment process enhanced the ability of ore kaolinite for $\mathrm{NH}_{4}{ }^{+}$removal from the aqueous solution.

\section{Conflict of Interests}

The authors declare that there is no conflict of interests regarding the publication of this paper.

\section{References}

[1] A. Ah and A. S. Ca, "Ammonia removal from an aqueous solution using chemical surface-modified sand," Health and the Environment Journal, vol. 3, no. 2, pp. 17-24, 2012.

[2] H. Yoon, J.-H. Lim, and H.-K. Chung, "Ammonia removal model based on the equilibrium and mass transfer principles," Bulletin of the Korean Chemical Society, vol. 29, no. 3, pp. 555$561,2008$.

[3] X. C. Zeng and Y. X. Li, Technology of Phosphorus and Nitrogen Removal From Wastewater, China Architectural Industry Press, Beijing, China, 1998.

[4] S. Uludag-Demirer, G. N. Demirer, and S. Chen, "Ammonia removal from anaerobically digested dairy manure by struvite precipitation," Process Biochemistry, vol. 40, no. 12, pp. 36673674, 2005.

[5] N. Segond, Y. Matsumura, and K. Yamamoto, "Determination of ammonia oxidation rate in sub- and supercritical water," Industrial and Engineering Chemistry Research, vol. 41, no. 24, pp. 6020-6027, 2002.

[6] M. K. Ghose, "Complete physico-chemical treatment for coke plant effluents," Water Research, vol. 36, no. 5, pp. 1127-1134, 2002.

[7] L. Lin, J. Chen, Z. Xu et al., "Removal of ammonia nitrogen in wastewater by microwave radiation: a pilot-scale study," Journal of Hazardous Materials, vol. 168, no. 2-3, pp. 862-867, 2009.

[8] N. Miladinovic and L. R. Weatherley, "Intensification of ammonia removal in a combined ion-exchange and nitrification column," Chemical Engineering Journal, vol. 135, no. 1-2, pp. 1524, 2008.

[9] P. Vassileva, P. Tzvetkova, and R. Nickolov, "Removal of ammonium ions from aqueous solutions with coal-based activated carbons modified by oxidation," Fuel, vol. 88, no. 2, pp. 387-390, 2009.

[10] H. Zheng, L. Han, H. Ma et al., "Adsorption characteristics of ammonium ion by zeolite 13X," Journal of Hazardous Materials, vol. 158, no. 2-3, pp. 577-584, 2008.

[11] E. Ivanova, M. Karsheve, and B. Koumanova, "Adsorption of ammonium ions onto natural zeolite," Journal of Chemical Technology and Metallurgy, vol. 45, no. 3, pp. 295-302, 2010.

[12] S. Balci and Y. Dinçel, "Ammonium ion adsorption with sepiolite: use of transient uptake method," Chemical Engineering and Processing, vol. 41, no. 1, pp. 79-85, 2002.

[13] L. Lin, Z. Lei, L. Wang X et al., "Adsorption mechanisms of highlevels of ammonium onto natural and $\mathrm{NaCl}$-modified zeolites," Separation and Purification Technology, vol. 103, no. 15, pp. 1520, 2013.
[14] K. G. Bhattacharyya and S. S. Gupta, "Adsorption of a few heavy metals on natural and modified kaolinite and montmorillonite: a review," Advances in Colloid and Interface Science, vol. 140, no. 2, pp. 114-131, 2008.

[15] K. G. Bhattacharyya and S. S. Gupta, "Influence of acid activation on adsorption of $\mathrm{Ni}(\mathrm{II})$ and $\mathrm{Cu}(\mathrm{II})$ on kaolinite and montmorillonite: kinetic and thermodynamic study," Chemical Engineering Journal, vol. 136, no. 1, pp. 1-13, 2008.

[16] S. S. Gupta and K. G. Bhattacharyya, "Using aqueous kaolinite suspension as a medium for removing phosphate from water," Adsorption Science \& Technology, vol. 30, no. 6, pp. 533-547, 2012.

[17] H. Cheng, Q. Liu, J. Yang, S. Ma, and R. L. Frost, "The thermal behavior of kaolinite intercalation complex-a review. Part I," Thermochimica Acta, vol. 545, pp. 1-13, 2012.

[18] M. Hassan and H. El-Shall, "Texture and microstructure of thermally-treated acid-leached kaolinitic clays," Adsorption Science and Technology, vol. 27, no. 7, pp. 671-684, 2009.

[19] H. P. Boehm, "Surface oxides on carbon and their analysis: a critical assessment," Carbon, vol. 40, no. 2, pp. 145-149, 2002.

[20] M. S. El-Geundi, T. E. Farrag, and H. M. A. Abd El-Ghany, "Adsorption equilibrium of a herbicide (pendimethalin) onto natural clay," Adsorption Science and Technology, vol. 23, no. 6, pp. 437-453, 2005.

[21] G. R. Armando, L. De La Torre, L. A. García-Serrano, and A. Aguilar-Elguézabal, "Effect of dialysis treatment on the aggregation state of montmorillonite clay," Journal of Colloid and Interface Science, vol. 274, no. 2, pp. 550-554, 2004.

[22] J. D. D. Melo, T. C. de Carvalho Costa, A. M. de Medeiros, and C. A. Paskocimas, "Effects of thermal and chemical treatments on physical properties of kaolinite," Ceramics International, vol. 36, no. 1, pp. 33-38, 2010.

[23] J. D. Kubicki, G. A. Blake, and S. E. Apitz, "Ab initio calculations on aluminosilicate $\mathrm{Q}_{3}$ species: implications for atomic structures of mineral surfaces and dissolution mechanisms of feldspars," American Mineralogist, vol. 81, no. 7-8, pp. 789-799, 1996.

[24] H. Suquet, "Effects of dry grinding and leaching on the crystal structure of chrysotile," Clays \& Clay Minerals, vol. 37, no. 5, pp. 439-455, 1989.

[25] H. Ming, "Modification of kaolinite by controlled hydrothermal deuteration-a DRIFT spectroscopic study," Clay Minerals, vol. 39, no. 3, pp. 349-362, 2004.

[26] S. Lagergren, "Zur theorie der sogenannten adsorption gelöster stoffe," Kungliga Svenska Vetenskapsakademiens. Handlingar, vol. 24, no. 4, pp. 1-39, 1989.

[27] Y.-S. Ho, "Review of second-order models for adsorption systems," Journal of Hazardous Materials, vol. 136, no. 3, pp. 681689, 2006.

[28] J. Ravichandran and B. Sivasankar, "Properties and catalytic activity of acid-modified montmorillonite and vermiculite," Clays and Clay Minerals, vol. 45, no. 6, pp. 854-858, 1997.

[29] W. J. Webeer and J. C. Morris, "Kinetics of adsorption of carbon from solution," Journal of Sanitary Engineering Division-ASCE, vol. 89, no. 2, pp. 31-59, 1963.

[30] Y. S. Ho and G. McKay, "Sorption of copper(II) from aqueous solution by Peat," Water, Air, and Soil Pollution, vol. 158, no. 1, pp. 77-97, 2004.

[31] I. Langmuir, "The adsorption of gases on plane surfaces of glass, mica and platinum," The Journal of the American Chemical Society, vol. 40, no. 9, pp. 1361-1403, 1918. 
[32] H. M. F. Freundlich, "Uber die adsorption in lösungen," Zeitschrift Für Physikalische Chemie, vol. 57, pp. 385-470, 1906.

[33] M. M. Dubinin and L. V. Radushkevich, "Equation of the characteristic curve of activated charcoal," Chemisches Zentralblatt, vol. 1, article 875, 1947.

[34] Y.-S. Ho, "Selection of optimum sorption isotherm," Carbon, vol. 42, no. 10, pp. 2115-2116, 2004.

[35] E. Bulut, M. Özacar, and I. A. Şengil, "Adsorption of malachite green onto bentonite: equilibrium and kinetic studies and process design," Microporous and Mesoporous Materials, vol. 115, no. 3, pp. 234-246, 2008. 

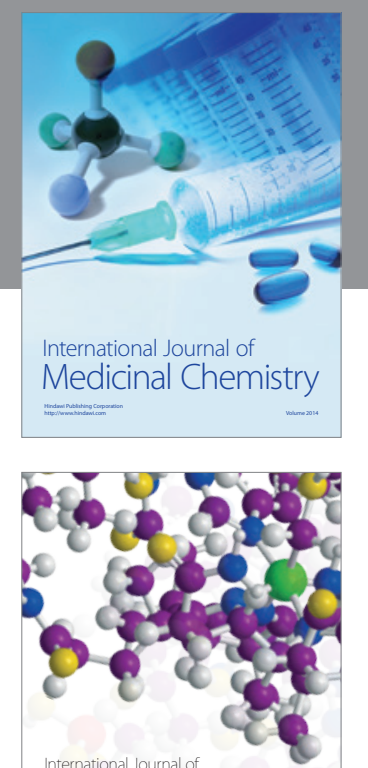

\section{Carbohydrate} Chemistry

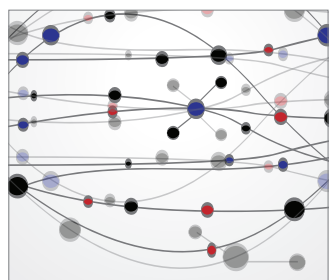

The Scientific World Journal
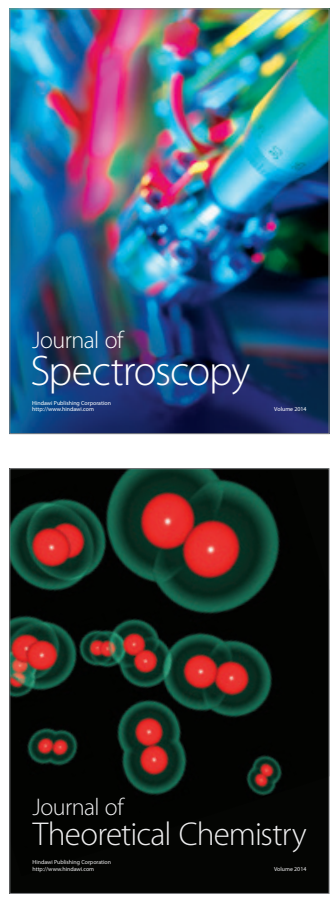
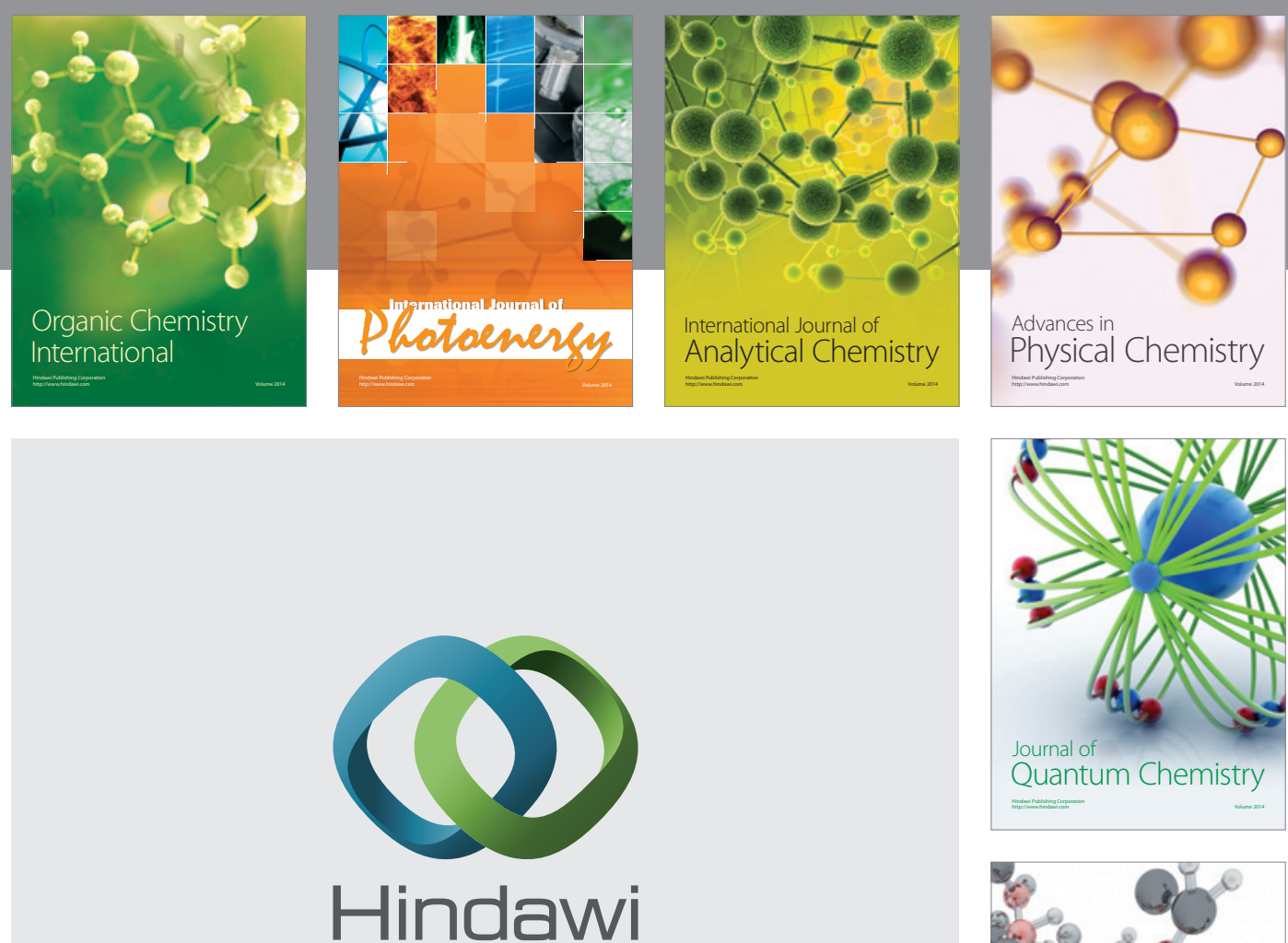

Submit your manuscripts at

http://www.hindawi.com

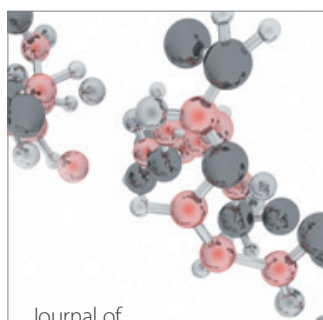

Analytical Methods

in Chemistry

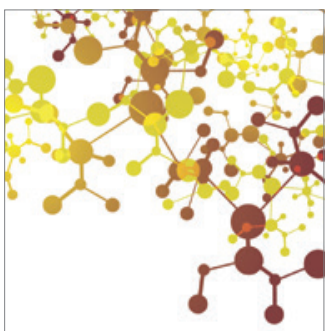

Journal of

Applied Chemistry

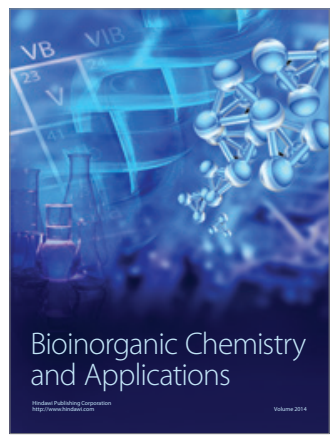

Inorganic Chemistry
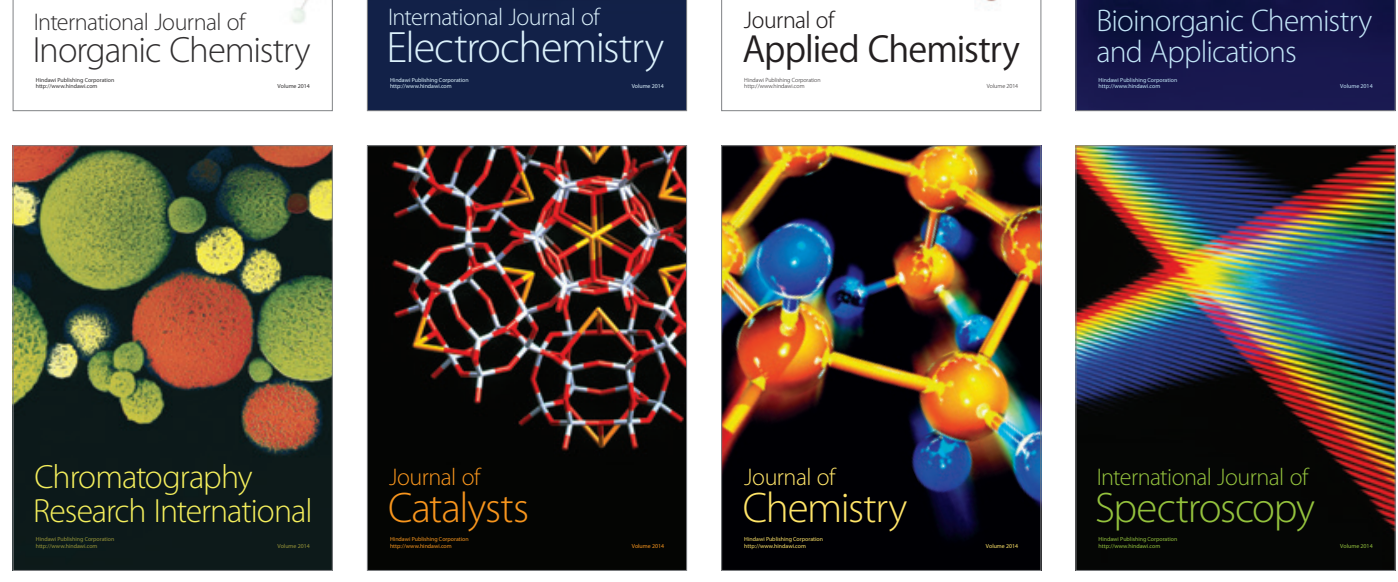